\title{
Seasonal variation in the invertebrate community and diet of a top fish predator in a thermally stable spring
}

\author{
Agnes-Katharina Kreiling ( E E Ein J. O’Gorman • Snæbjörn Pálsson • \\ David Benhaïm • Camille A. Leblanc • Jón S. Ólafsson • Bjarni K. Kristjánsson
}

Received: 7 January 2020/Revised: 28 August 2020/Accepted: 7 September 2020/Published online: 18 September 2020

(C) The Author(s) 2020

\begin{abstract}
Many life-history events in aquatic invertebrates are triggered by seasonal changes in water temperature, but other ecological factors may be important as well. To rule out the confounding effects of changing water temperature, we studied the seasonal dynamics of an aquatic invertebrate community and their effect on a top fish predator in a thermally stable freshwater spring in South Iceland. We sampled benthic invertebrates five times over a year and conducted a mark-recapture study on the top predator in the system, small benthic Arctic charr, Salvelinus alpinus (L.). We assessed variation in diet composition and feeding preferences by calculating the electivity and individual specialisation of each fish
\end{abstract}

Handling editor: Katya E. Kovalenko

A.-K. Kreiling $(\varangle) \cdot$ D. Benhaïm .

C. A. Leblanc · B. K. Kristjánsson

Department of Aquaculture and Fish Biology, Hólar

University, Háeyri 1, 550 Sauðárkrókur, Iceland

e-mail: kreiling@holar.is

\section{A.-K. Kreiling · S. Pálsson}

University of Iceland, Institute of Life and Environmental

Sciences, Askja, Sturlugata 7, 101 Reykjavík, Iceland

\section{E. J. O'Gorman}

School of Life Sciences, University of Essex, Wivenhoe Park, Colchester CO4 3SQ, UK

J. S. Ólafsson

Marine and Freshwater Research Institute, Skúlagata 4,

101 Reykjavík, Iceland at each sampling time. There was a clear separation of winter and summer communities for the benthic invertebrates. The variation in prey availability was also reflected in the fish diet, with higher feeding selectivity in summer than in winter for the highly abundant Chironomidae larvae. In contrast, individual specialisation as a measure of intrapopulation niche variation was higher in winter when prey availability was lower. We furthermore found that groundwater amphipods might play an important role in the winter diet of spring-dwelling Arctic charr. In conclusion, seasonal variation in the invertebrate community is an important factor to consider and has the potential to alter the phenotype (e.g. growth rates) and behaviour (e.g. feeding preferences) of higher trophic levels.

Keywords Feeding selectivity - Individual specialisation - Arctic charr - Salvelinus alpinus . Phenology

\section{Introduction}

Temperature determines the metabolic demands of all ectothermic organisms (Brown et al., 2004). Water temperature is thus a crucial factor shaping individual life-histories, community composition, and food webs in freshwater ecosystems. Seasonal temperature change is a cue that triggers life-history events in many aquatic invertebrates (e.g. emergence and 
diapause) (Ward \& Stanford, 1982). Altered temperatures can also lead to changes in community composition and food web structure in freshwater ecosystems (Petchey et al., 1999; Burgmer et al., 2007; Shurin et al., 2012; O'Gorman et al., 2017, 2019). For example, increasing temperature can lead to greater fish production, driven by behavioural changes in feeding selectivity and altered energy flow through the food web (O'Gorman et al., 2016).

Because temperature affects organisms on so many different levels, it can be hard to disentangle temperature effects from other variables in ecological field studies. Here, we take advantage of a natural setting in which temperature is independent of major seasonal changes, a thermally stable groundwater-fed spring, to study the seasonal variation in its invertebrate community and the diet of a fish predator. Freshwater springs are stable environments with little seasonal fluctuation in temperature, $\mathrm{pH}$, conductivity, and oxygen concentration (van der Kamp, 1995; Szczucinska \& Wasielewski, 2013). Nevertheless, there are clear seasonal differences in the aquatic invertebrate communities of springs (Nolte, 1991; Bottazzi et al., 2011; Berlajolli et al., 2019). These seasonal differences are mostly driven by aquatic insects with an aerial dispersal stage (e.g. Diptera, Trichoptera, Plecoptera), whose larvae dominate the invertebrate community in spring and summer, whereas wholly aquatic taxa (e.g. Ostracoda, Copepoda, aquatic Coleoptera) are relatively more abundant during the winter months. Thus, the summer and winter invertebrate communities in springs are notably different (Berlajolli et al., 2019). Seasonal variation in invertebrate abundance and community structure can have implications for higher trophic levels. Prey availability can affect a predator in various aspects and at various life stages, for example in relation to morphology (Kristjánsson et al., 2012; Kristjánsson \& Leblanc, 2018), growth rates (Amundsen et al., 2007; O'Gorman et al., 2016), and feeding behaviour (Emlen, 1966; O’Gorman et al., 2016).

Optimal foraging theory predicts feeding strategies to be a trade-off between resource quality, distribution, and abundance (Emlen, 1966; Stephens \& Krebs, 1986). When prey availability in the environment is scarce, a generalist predator could consume a broad selection of the mixed quality prey it encounters, minimising time spent foraging; or it may invest more effort into searching for nutrient-rich prey, maximising the energy gained from a smaller quantity consumed (Schoener, 1971). When prey availability is high, it might be even more beneficial to actively select prey items with the highest energetic gain (Emlen, 1966). In that case, we would expect a consumer to feed more selectively when prey abundance is high. Selective feeding behaviour, where consumers actively choose high quality resources over more abundant, lower quality resources has been documented for a wide range of animals, including insects (Haslett, 1989; Klecka \& Boukal, 2012), birds (Zwarts \& Blomert, 1990; Schaefer \& Schaefer, 2006), mammals (Evans et al., 2006; Jones \& Norbury, 2011), and fishes (Uieda \& Pinto, 2011; Tófoli et al., 2013; O’Gorman et al., 2016).

To evaluate resource use at the individual level, one can compare the diet of an individual to the food availability in the environment, for example using indices of feeding selectivity. Another approach is to calculate the individual diet specialisation, which measures the proportion of the dietary niche of the whole population used by an individual (i.e. the intrapopulation niche variation) (Bolnick et al., 2002). To estimate individual diet specialisation, an individual's diet is compared to the population's diet, rather than to food availability in the environment. Quantifying diet with both methods gives the best overview of individual variation in resource use. Individual diet specialisation is common in many animal groups (Araújo et al., 2011) and likely ubiquitous in nature. But the levels of individual specialisation may vary among populations of the same species (Bolnick et al., 2003, Araújo et al., 2011, Kristjánsson \& Leblanc, 2018), and depend on a variety of ecological factors such as intra- and inter-specific competition, predation, parasitism, and diversity and availability of resources (Darimont et al., 2007; Costa et al., 2008; Araújo et al., 2011; Svanbäck et al., 2011; Tinker et al., 2012; Britton \& Andreou, 2016). There is evidence that individual diet specialisation is flexible within the same individual and varies with environmental conditions (Zango et al., 2019). For example, diet specialisation has been found to be higher when resource availability is low (Svanbäck et al., 2011).

Individual specialisation has been studied in northern freshwater fishes, including Arctic charr [Salvelinus alpinus (Linnaeus, 1758)] (Kristjánsson \& Leblanc, 2018). Arctic charr is known for its high diversity (Klemetsen, 2013), and several discrete 
morphs often occur in sympatry, differing in morphology (Skúlason et al., 1989), genetics (Skúlason et al., 1996), preferred habitat (Kristjánsson et al., 2012), and diet (Malmquist et al., 1992). One of the morphs, the small benthic ( $<15 \mathrm{~cm}$ adult length), is often found in springs and spring-fed streams and ponds (Kristjánsson et al., 2012), and represents one of the top predators in Icelandic freshwater springs.

In this study, we investigated how seasonal variation in abundance and composition of an aquatic invertebrate community affects a top fish predator, independent of the confounding effects of seasonal temperature change. We hypothesised that: (1) the benthic invertebrate community varies between seasons, with distinct winter and summer communities; (2) changes in invertebrate community composition are reflected in the diet of Arctic charr; and (3) feeding selectivity of Arctic charr is higher and individual specialisation lower in seasons with high invertebrate abundance.

\section{Materials and methods}

Sampling site

The study site was the spring of the small stream Skarðslækur $\left(64^{\circ} 00.306^{\prime}\right.$ N 2007.110' W, 103 m asl) in South Iceland. Groundwater emerges from several distinct sources and runs off as shallow streams (depth $<0.5 \mathrm{~m}$ ), merging into a single main channel a few meters downstream. The substrate of the stream is mainly comprised of lava rock near the spring sources and smaller stones, gravel, and sand farther downstream. Small benthic Arctic charr are common in the spring region and even seek shelter in the sources (Kristjánsson et al., 2012). Arctic charr are seemingly scarce in the main channel, where the substrate is predominated by sand. The total surface area fished at each sampling occasion was $333 \mathrm{~m}^{2}$, subdivided into six smaller sampling zones: a, b, c, d, e, and f (Fig. 1), which differed in substrate characteristics and number of spring sources. Temperature, electric conductivity, oxygen saturation, and $\mathrm{pH}$ of each sampling location were measured on each sampling occasion, using a Hydrolab DS5 multi-probe sonde (Hach Hydromet, Loveland, CO, USA). In addition, a HOBO temperature logger (Onset Computer Corporation, Bourne,
MA, USA), measuring at 2-h intervals, was placed at the site for 1 year to provide a detailed thermal profile.

Fish processing

We conducted a mark-recapture study between May 2017 and March 2018, visiting the site five times during that period (in May, June, August, October 2017, and March 2018). On each sampling occasion, fish were captured by electrofishing and processed onsite. Fish were anesthetised with 2-phenoxyethanol (300 ppm), and fork length and wet weight were measured for every individual. Stomach contents were collected for diet analysis of fish with a fork length $\geq 55 \mathrm{~mm}$ by inserting a plastic catheter attached to a syringe through the mouth as far as the anterior part of the stomach and flushing its content out with clear water (Meehan \& Miller, 1978). Invertebrates in the stomach samples were preserved in $70 \%$ ethanol until identification. Fish with a fork length $\geq 65 \mathrm{~mm}$ were then tagged by implanting a Passive Integrated Transponder (PIT tag, 12 mm HDX, Oregon RFID, Portland, OR, USA) through a small incision into the abdominal cavity upon first capture. Each PIT tag has a unique code which can be read by a handheld field scanner (Tags4all Inc., Mitchell, Ontario). After processing, the fish were allowed to recover before they were released back into the spring at the location where they were caught.

Population density, biomass, and growth rate of Arctic charr

Population size $(N)$ of Arctic charr was estimated using the Petersen estimator $N=\frac{m \times c}{r}$, with $m=$ total number of marked fish in the system, $c=$ number of fish captured, and $r=$ number of marked fish recaptured (Robson \& Regier, 1964). Population size was calculated for June, August, and October, and averaged. We did not estimate population size for March, due to a very low recapture rate of only four fish, and because numbers would have been biased due to removal of fish from the spring for behavioural studies in the laboratory after the sampling in October. Population density $(D)$ in the spring was then estimated as $D=N / A$, with $A=$ surface area fished. Population biomass $(B)$ was calculated as $B=\bar{M} \times D$, with $\bar{M}=$ mean body mass during sampling event. 


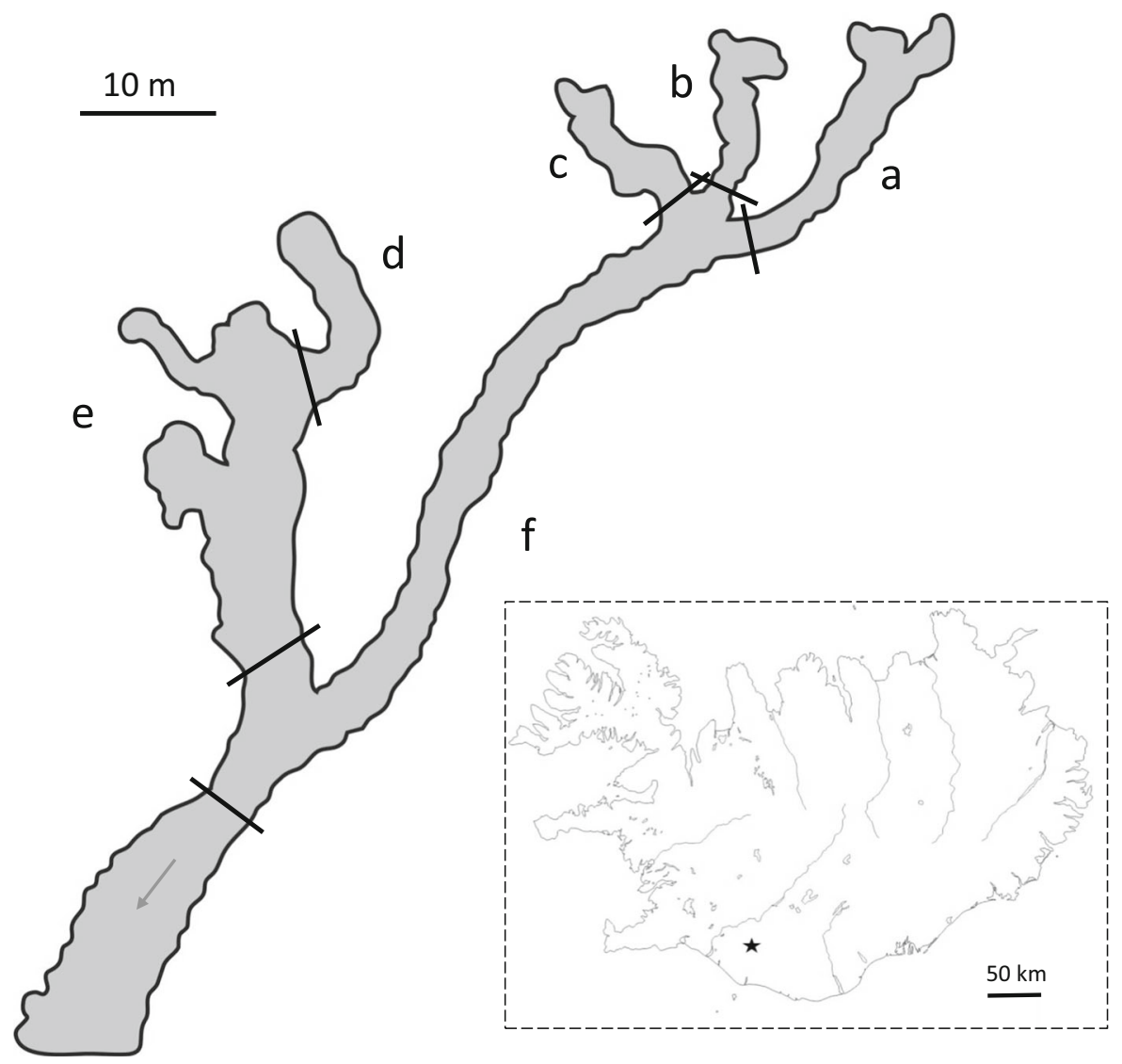

Fig. 1 Map of the spring region of the study stream, Skarðslækur in South Iceland. Lines and letters (a, b, c, d, e, f) indicate division of the site into different sampling zones. The star in the figure inset shows the location of the sampling site in South Iceland

Growth rate $(G)$ between sampling events was calculated as $G=\frac{M_{2}-M_{1}}{t}$, with $M_{1}$ and $M_{2}$ as initial and final weight of recaptured fish in grams, and $t=$ number of days between sampling events. We calculated the body condition of the fish according to Barnham \& Baxter (1998) as $K=\frac{10^{5} \times W}{L^{3}}$, with $W=$ weight in grams and $L=$ fork length in millimetres.

Invertebrate availability and diet composition

To study seasonal variation in the invertebrate community and estimate prey availability in the habitat, we collected invertebrates from the benthic substrate of the spring. Due to logistical reasons, samples were only taken at two zones of the spring (a and d, Fig. 1) on each sampling occasion, using a $0.093 \mathrm{~m}^{2}$ Surber sampler with $63 \mu \mathrm{m}$ mesh. Arctic charr feed in a variety of microhabitats in streams, such as stony substrate, macrophytes, and near the banksides. Thus, one Surber sample was collected from each of these three microhabitats and pooled, resulting in a sampled surface area of $0.279 \mathrm{~m}^{2}$ per sample. Samples were stored in $70 \%$ ethanol until processing.

Invertebrates in the samples were counted and pooled into nine groups to facilitate comparison between the benthos and the diet of Arctic charr, i.e. there would be too many zeros in the dataset if comparisons were performed on a species-level basis (see also O'Gorman et al., 2016). The nine prey groups were: Chironomidae larvae, Ostracoda, Copepoda, Acarina, Trichoptera larvae/Plecoptera nymphs, predatory Diptera larvae [not including Chironomidae, and largely consisting of Limnophora riparia (Fallén, 1824)], Oligochaeta (including earthworms), aerial insects (largely consisting of adult stages of Diptera, Plecoptera, and Trichoptera), and miscellaneous rare taxa (including Cladocera, Amphipoda, aquatic Coleoptera larvae and adults, and 
Collembola). Note that organisms in the miscellaneous group were occasionally found in fish stomachs, but were absent in the benthic samples (except for Cladocera). Since the aerial and miscellaneous groups were not systematically sampled and only stochastically represented in the benthic samples, a comparison between their relative abundance in the fish diet and in the environment was not possible, and they were thus excluded from the analysis of feeding selectivity. Fish with empty stomachs $(n=61$ out of 692$)$ were also excluded from further analysis.

The selectivity $\left(S_{i}\right)$ of Arctic charr feeding on each of the prey groups was calculated as:

$S_{i}=\frac{d_{i} / b_{i}}{\sum_{j=1}^{n} d_{j} / b_{j}}$,

where $d$ and $b$ were the relative abundance of each prey group in the diet and in the benthic invertebrate samples, respectively (Chesson, 1983). We then calculated the Relativized electivity index $E_{i}$ (Vanderploeg \& Scavia, 1979; Lechowicz, 1982), as:

$E_{i}=\left(S_{i}-\frac{1}{n}\right) /\left(S_{i}+\frac{1}{n}\right)$,

where $n=$ number of prey groups available. Values of $E_{i}$ range from -1 to +1 , with negative values indicating avoidance of prey, positive values indicating selection, and a value of zero indicating random feeding.

To estimate individual specialisation (i.e. the diet overlap between an individual and the population as a whole), we used the proportional similarity index:

$P S_{i}=1-0.5 * \sum_{j}\left|p_{i j}-q_{j}\right|$

where $p_{i j}$ is the proportion of the $j$-th prey group consumed by the population which is also consumed by individual $i$, and $q_{j}$ is the proportion of the $j$-th prey group in the population's diet (Schoener, 1968; Feinsinger et al., 1981; Bolnick et al., 2002). $P S_{i}$ values range from 0 (strong specialisation) to 1 (generalisation). We then calculated the populationwide prevalence of individual specialisation, $I S$, as the average of an individual's $P S_{i}$ values for each sampling month. $S_{i}, E_{i}$, and $P S_{i}$ were calculated only for fish with prey items in their stomachs.
Statistical analysis

All statistical analyses were performed in R 3.4.1 ( $\mathrm{R}$ Core Team, 2016). Multivariate analyses were required throughout because changes in the relative abundance of, electivity for, or individual specialisation on a particular prey group will implicitly result in altered relative values of one or more of the other prey groups. Differences in the benthic invertebrate community in the spring and in the diet composition of Arctic charr between sampling months were analysed using a permutational multivariate analysis of variance (PERMANOVA; adonis function in the vegan package; Oksanen et al., 2017). A similarity percentage analysis (SIMPER; simper function in the vegan package) based on Bray-Curtis distances was performed to compare taxonomic differences in invertebrate community and diet composition between the five sampling months. The effects of sampling month, sampling zone in the spring, body length, and body condition of fish (explanatory variables) on the feeding electivity, $E_{i}$, and individual specialisation, $P S_{i}$, (response variables) were tested with a PERMANOVA and visualised with non-metric multidimensional scaling (NMDS). The weighted averages of the prey groups were calculated (wascores function in the vegan package; Oksanen et al., 2017) and shown in the NMDS plots to identify prey groups that were driving electivity and individual specialisation. Dissimilarity matrices were based on Euclidean distances, which is appropriate when zero-values (here: no selectivity) are relevant to the hypothesis being tested (Clarke et al., 2006).

\section{Results}

Environmental variables

The water temperature of the spring was extremely stable over the course of the year at $5.5 \pm 0.26^{\circ} \mathrm{C}$ (mean \pm standard deviation). The lowest temperature measured was $4.8^{\circ} \mathrm{C}$ and the highest was $7.4^{\circ} \mathrm{C}$. The daily fluctuation in water temperature ranged from $0.03 \pm 0.048^{\circ} \mathrm{C}$ in January to $0.60 \pm 0.487^{\circ} \mathrm{C}$ in July. Other environmental variables were also similar on the five sampling occasions, with average oxygen saturation of $75.2 \pm 0.99 \%, \mathrm{pH}$ of $7.3 \pm 1.03$, and conductivity of $138 \pm 29.7 \mu \mathrm{S} \mathrm{cm} \mathrm{cm}^{-1}$. This confirms the 
environmental and thermal stability of the Skarðslækur spring, providing a semi-controlled experimental setting.

Population density and growth rate of Arctic charr

Among a total of 472 tagged fish, we obtained 55 recaptures, with a few individuals recaptured multiple times. The population size $(N)$ of Arctic charr in the spring region of Skarðslækur was estimated to be 1920 $( \pm 244)$ fish, resulting in a population density of 5.8 fish $\mathrm{m}^{-2}$. Fish were not captured evenly across the sampled area but mainly close to the sources. Population biomass $(B)$ was highest in May at $32.48 \mathrm{~g} \mathrm{~m}^{-2}$, and lowest in March at $22.04 \mathrm{~g} \mathrm{~m}^{-2}$ (Table 1). Average growth rates were highest between June and August at $0.13 \pm 0.103 \mathrm{~mm} \mathrm{~d}^{-1}$, as opposed to $0.09 \pm 0.060 \mathrm{~mm} \mathrm{~d}^{-1}$ between August and October, and $0.04 \pm 0.031 \mathrm{~mm} \mathrm{~d}^{-1}$ between May and June.

Seasonal variation in invertebrate community

The total abundance of invertebrates in the benthic samples varied over the year, ranging from 1306 in May to 5967 in June (Table 1). Chironomidae larvae were by far the most abundant group on all five sampling occasions, reaching up to 4591 individuals in June. The second most abundant group were Ostracoda, with a maximum abundance of 587 in August. Other invertebrate groups were less abundant but still exhibited clear seasonal changes, for example larvae of Trichoptera/Plecoptera and predatory Diptera were most abundant in October, while Copepoda and Acarina peaked in June. The invertebrate community in the spring differed between sampling months, supporting our first hypothesis $\left(\mathrm{Fp}=3.80, \mathrm{r}^{2}=0.75\right.$, $P=0.022, \mathrm{Df}_{\text {Month }}=4, \mathrm{Df}_{\text {Residuals }}=5$; Fig. 2a). The highest average between-groups dissimilarities based on the SIMPER analysis were between June and March (65.9\%) and May and June (64.8\%), the lowest between August and October (15.7\%). Dissimilarities of pairwise comparisons between the other months ranged from $31.7 \%$ (May-March) to $45.7 \%$ (AugustMarch). The taxa contributing most to these differences were Chironomidae larvae, followed by Oligochaeta (Fig. 2a).

Diet composition, feeding selectivity, and individual specialisation of Arctic charr

The most abundant prey groups in the stomach samples were Chironomidae larvae (with a total of 15233 in 635 Arctic charr stomachs), followed by aerial insects (1714), the miscellaneous group (150), predatory Diptera larvae (1226), and Ostracoda (826). As for the benthic invertebrate community, there was seasonal variation in the abundance of prey groups in the diet, for example the highest abundance of Ostracoda and Acarina occurred in March (Fig. 2b). The miscellaneous group in the diet was dominated by groundwater amphipods in March, but consisted mainly of Cladocera and aquatic Coleoptera in all other sampling months. The proportion of fish caught with empty stomachs was higher in winter and early summer, with $12 \%$ in March and $16 \%$ in May, compared to $6-7 \%$ in June, August, and October. Note that these patterns mirror total invertebrate abundance in the environment (Table 1). For fish with

Table 1 Temporal distribution of invertebrates in the benthic habitat of the spring and in the stomachs of Arctic charr

\begin{tabular}{|c|c|c|c|c|c|c|}
\hline Month & Total invert. & Total stomachs & Prey items & Prey groups & $\begin{array}{l}B \\
{\left[\mathrm{~g} * \mathrm{~m}^{2}\right]}\end{array}$ & $P S_{i}$ \\
\hline May & 1306 & 99 (16 empty) & $34 \pm 44.5$ & $2.3 \pm 1.12$ & 32.48 & $0.71 \pm 0.22$ \\
\hline June & 5967 & 181 (13 empty) & $22 \pm 42.6$ & $2.2 \pm 1.22$ & 29.00 & $0.69 \pm 0.16$ \\
\hline August & 3318 & 146 (11 empty) & $44 \pm 75.2$ & $2.6 \pm 1.23$ & 30.74 & $0.76 \pm 0.14$ \\
\hline October & 3000 & 183 (11 empty) & $33 \pm 50.9$ & $3.0 \pm 1.47$ & 31.32 & $0.65 \pm 0.16$ \\
\hline March & 1379 & 83 (10 empty) & $19 \pm 28.9$ & $2.6 \pm 1.28$ & 22.04 & $0.44 \pm 0.16$ \\
\hline
\end{tabular}

Columns include the total number of invertebrates in the benthic samples (Total invert.), the total number of fish stomachs examined (with number of empty stomachs in brackets), average number of prey items per fish ( \pm standard deviation), average number of prey groups per fish ( \pm standard deviation), population biomass $(\mathrm{B})\left[\mathrm{g}^{*} \mathrm{~m}^{2}\right]$, and average individual specialisation $\left(P S_{i} \pm \mathrm{standard}\right.$ deviation) in the diet. The values of $P S_{i}$ range from 0 (strong specialisation) to 1 (generalisation) 
(a) Benthic samples

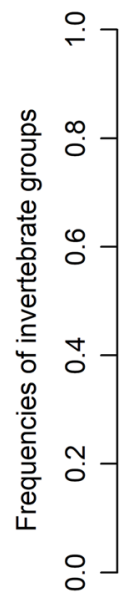

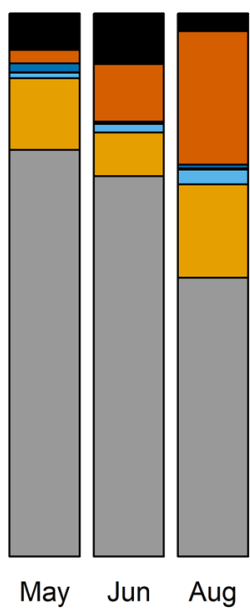

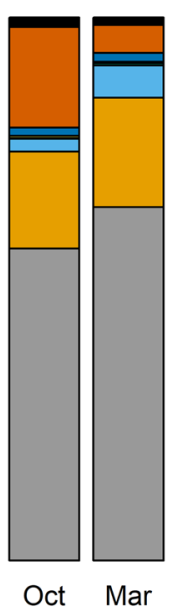

(b) Fish diet
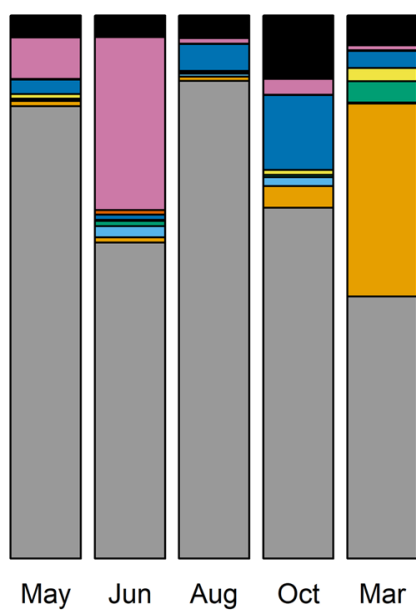

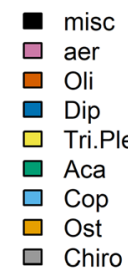

Sampling month

Fig. 2 Invertebrate composition in a the benthic samples and b Arctic charr stomachs over the five sampling months. The number of stomachs sampled in each month is shown in Table 1. Prey groups are abbreviated in the legend as follows: Chiro

prey in their stomachs, the average number of prey items per individual ( \pm standard deviation) was $31 \pm 53.6$, belonging to $2.5 \pm 1.32$ of the nine invertebrate groups (Table 1). The diet composition of Arctic charr differed between sampling months, supporting our second hypothesis $(\mathrm{Fp}=27.56$, $r^{2}=0.16, P=0.001, \mathrm{Df}_{\text {Month }}=4, \mathrm{Df}_{\text {Residuals }}=599$; Fig. 2b). The highest dissimilarities in the diet composition were between May and June (64.9\%) and June and March (65.9\%), and the lowest between August and October (15.7\%) (SIMPER analysis).

The large number of Chironomidae larvae in the fish stomachs reflected their abundance in the benthic environment, and they were often proportionally higher in the diet compared to the benthos (Fig. 3a). Invertebrate groups such as Acarina, Trichoptera/ Plecoptera larvae, and predatory Diptera larvae, were also proportionally high in the diet compared to the benthic samples (Fig. 3d, e, f). On the other hand, Ostracoda and Oligochaeta were proportionally low in the diet on all sampling occasions (Fig. 3b,g) despite their high abundance in the benthic samples. This suggests selective feeding of fish, but median values of $E_{i}$ were negative (indicating avoidance of prey) for all prey groups and all sampling months, except for Chironomidae larvae in June (Fig. 4). However, there was large variation in $E_{i}$ among fish (Fig. 4), and
(Chironomidae larvae), Ost (Ostracoda), Cop (Copepoda), Aca (Acarina), Tri.Ple (Trichoptera/Plecoptera larvae), Dip (predatory Diptera larvae), Oli (Oligochaeta), aer (aerial insects), and misc (miscellaneous)

several individuals showed feeding preferences for Chironomidae larvae throughout the year (Fig. 4a), for predatory Diptera larvae in August, October, and March (Fig. 4f), and for Trichoptera/Plecoptera larvae (Fig. 4e) in March. There was no clear general pattern linking feeding selectivity to total invertebrate abundance in the environment, in contrast to our third hypothesis (Table 1). While fish preferred some prey groups such as Chironomidae, Copepoda, and Oligochaeta in June (when total invertebrate abundance was high), there was a stronger preference for Ostracoda and Trichoptera/Plecoptera in March (when total invertebrate abundance was low).

Sampling months, sampling zone in the spring, and body length of fish contributed to the individual variation in relative electivity between fish (Table $2 a$ ). Body length was positively correlated with a preference for predatory Diptera larvae (Fig. 5a). Although body condition was marginally non-significant in the PERMANOVA (Table 2), it was positively correlated with a preference for Trichoptera/Plecoptera larvae and predatory Diptera larvae (Fig. 5a).

Average individual specialisation $\left(P S_{i}\right)$ was much higher in March than during the summer, as reflected by a low $P S_{i}$ value (Table 1), indicating that individuals in the population became more specialised in winter than in summer. The highest individual 
(a) Chironomidae larvae

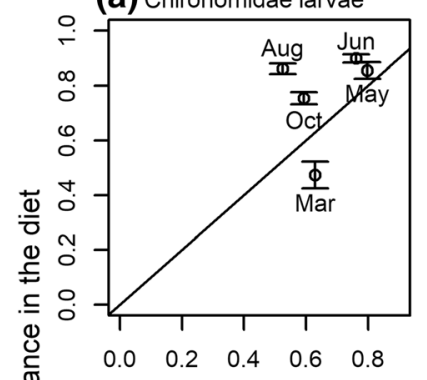

(e) Trichoptera/Plecoptera

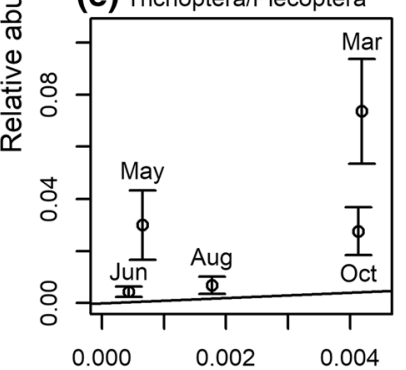

(b) Ostracoda

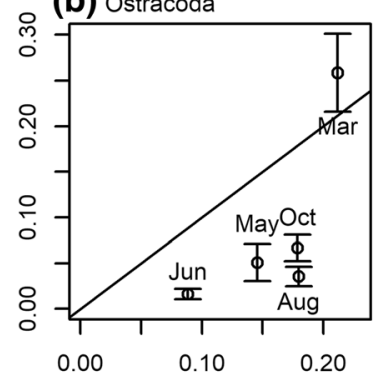

(f) Predatory Diptera larvae

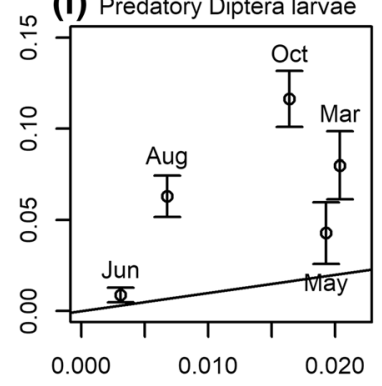

(c) Copepoda
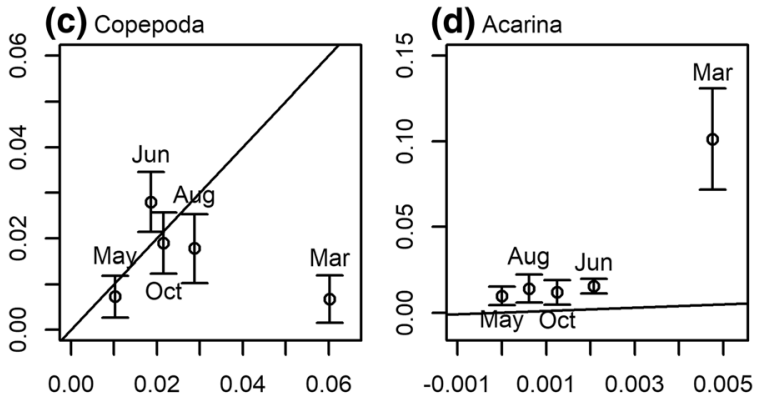

(g) Oligochaeta

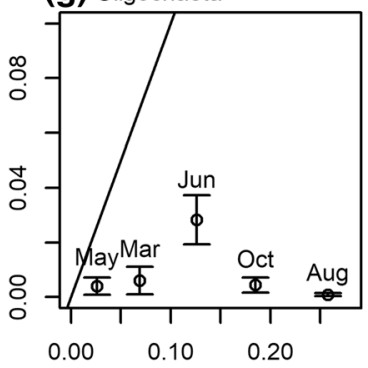

Relative abundance in the environment

Fig. 3 Relationship between invertebrate groups in the diet of Arctic charr and their availability in the benthic environment. The average proportion of invertebrate groups in the stomach samples (mean \pm standard error) are plotted against the average proportion of those groups in the benthos for each of the five sampling months, which are indicated with a label next to the data point that corresponds to each sampling month. The black

specialisation in March coincided with the time of the lowest invertebrate abundance, partially supporting our third hypothesis (Table 1). Variation in individual specialisation for the nine prey groups was influenced by sampling months, sampling zone in the spring, and body length of fish, but not by body condition (Table 2b). Smaller fish in the population specialised more on Ostracoda and Acarina as food items, whereas bigger fish specialised more on Oligochaeta, particularly large earthworms (Fig. 5b).

\section{Discussion}

The benthic invertebrate communities in Skarðslækur in winter (March) and spring (May) were analogous to each other, but very dissimilar from the communities in summer (June and August) and autumn (October), which were in turn very similar. This grouping into winter/spring and summer/autumn communities supports our first hypothesis and is in line with the results line is a regression line with a slope of 1 ; points below the line indicate that the item is more abundant in the environment than in the diet; points above the line indicate that the item is more abundant in the diet than in the environment. Note that aerial insects and the miscellaneous group were not adequately sampled in the environment and thus are not shown in the figure

of a study on the seasonality of invertebrate communities in mountain springs in Kosovo (Berlajolli et al., 2019). The high dissimilarity between consecutive months in May and June suggests a rapid transition between spring and summer, possibly triggered by emergence and oviposition of aquatic insects with an aerial adult stage.

The seasonal variation in abundances seen in the benthic invertebrates can mostly be explained by the life-histories of the taxa. Many crustacean species (e.g. Cladocera and Ostracoda) undergo a clear seasonal periodicity, with very low abundances during the winter when reproduction ceases and populations consist mainly of resting stages (eggs and diapausing individuals) (Pennak, 1953). Similarly, many water mites (Hydrachnidia) are less active during winter months and most adults are generally found in spring and early autumn, though seasonal dynamics vary a lot among species (Pennak, 1953; Schmidt, 1969). Many aquatic insects with an aerial adult stage emerge in early spring to late summer, and oviposit shortly after. 

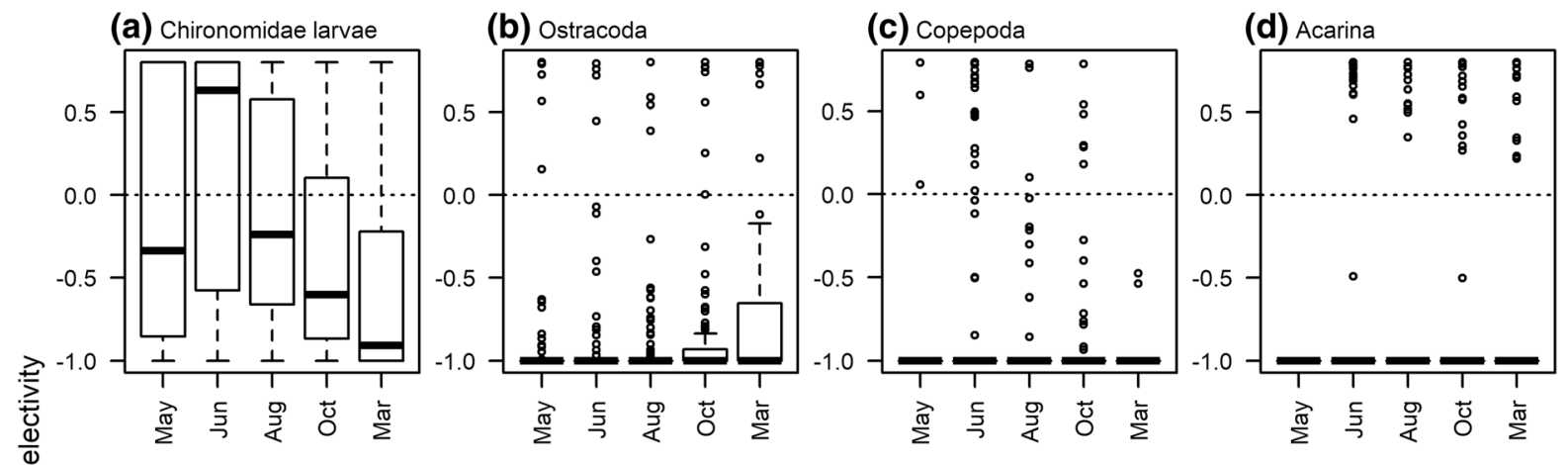

(e) Trichoptera/Plecoptera
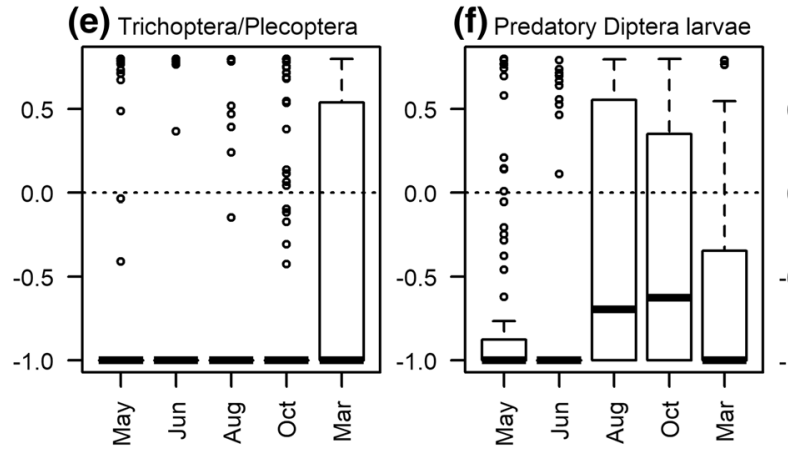

(g) Oligochaeta

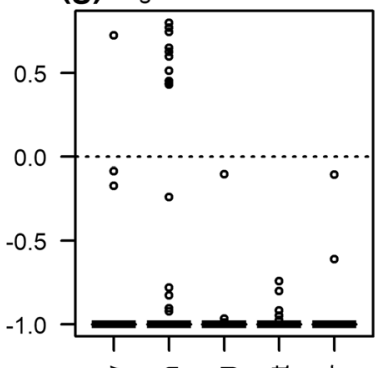

Sampling month

Fig. 4 Distribution of relative electivity $E_{i}$ of Arctic charr on five sampling occasions (May, June, August, and October 2017, and March 2018). Boxplots show the interquartile range (box) of the data point distribution, minimum and maximum values (whiskers), the median (black line), and outliers (dots). A positive value (above the dotted line) of $E_{i}$ indicates selectivity for the prey group, whereas a negative value (below the dotted line) indicates avoidance of the prey group. Note that aerial insects and the miscellaneous group were not adequately sampled in the environment and thus $E_{i}$ was not calculated for these prey groups
Table 2 Dependency of explanatory variables on (a) relative electivity $\left(E_{i}\right)$ and (b) individual specialisation $\left(P S_{i}\right)$ of Arctic charr

\begin{tabular}{llllll}
\hline Response variable & Explanatory variable & Df & Fp & $r^{2}$ & $P$-value \\
\hline (a) $E_{i}$ & & & & & \\
& Sampling month & 4 & 13.853 & 0.087 & $<0.001^{* * *}$ \\
& Sampling zone & 5 & 2.387 & 0.019 & $<0.001^{* * *}$ \\
& Body length & 1 & 5.533 & 0.009 & $<0.001^{* * *}$ \\
& Body condition & 1 & 1.970 & 0.003 & 0.082 \\
& Residuals & 559 & & 0.882 & \\
(b) $P S_{i}$ & Sampling month & 4 & 31.139 & 0.178 & $<0.001^{* * *}$ \\
& Sampling zone & 5 & 1.653 & 0.018 & $0.043^{*}$ \\
& Body length & 1 & 5.592 & 0.008 & $0.002^{* *}$ \\
& Body condition & 1 & 0.527 & 0.001 & 0.727 \\
\hline
\end{tabular}

Asterisks (*) indicate the level of significance for each $P$-value (where $*<0.05, * *<0.01$, and $* * *<0.001)$ can be found during most of that time, and the October peak in abundance of Trichoptera larvae seen in our data marks the end of the reproductive season before the winter mortality of larvae begins (Gíslason, 1978, 1992). 
(a) Relative electivity

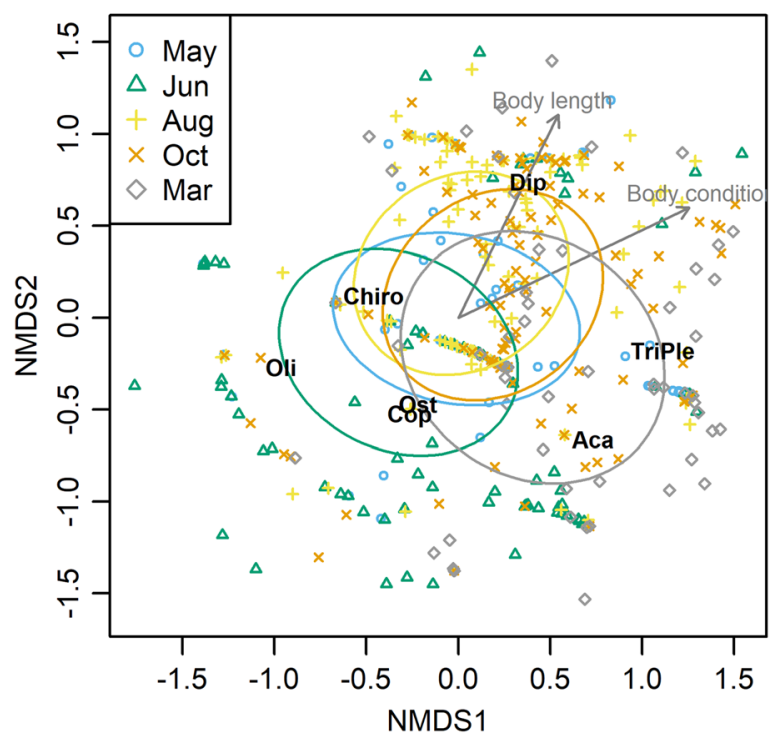

Fig. 5 Non-metric multidimensional scaling (NMDS) plots illustrating the (a) relative electivity $\left(E_{i}\right)$ and (b) individual specialisation of Arctic charr in the study stream. The five sampling months are coded by symbols and colours (defined in the legends of each panel), with coloured ellipses indicating the confidence region for the centroids of each month. The weighted averages of prey groups are indicated with black text, and their correlations with body length and body condition of fish are indicated with grey vectors and labels. Body condition did not explain significant variation in individual specialisation (see

Since water temperatures were stable over the year in the studied spring system, invertebrate life-history events like hatching, emergence, or end of dormancy must be triggered by other cues. Multiple variables, both internal (e.g. sex, body size) and environmental (e.g. photo- or hydroperiod, chemicals in the environment), can interact to determine the onset of lifehistory events in invertebrates (Nylin \& Gotthard, 1998; Shama \& Robinson, 2006). Possible candidates for environmental cues acting on aquatic insects are changes in photoperiod (Lutz, 1974), primary production, and thus food availability for primary consumers (Anderson \& Cummins, 1979).

The SIMPER analysis revealed the same pattern of pairwise dissimilarities between the diet composition of Arctic charr in different months as for the benthic invertebrate communities in those months, supporting our second hypothesis. The diet composition of Arctic charr was similar during winter/spring (March and May) and during summer/autumn (June, August, and October), but differed between these two periods. (b) Individual specialisation

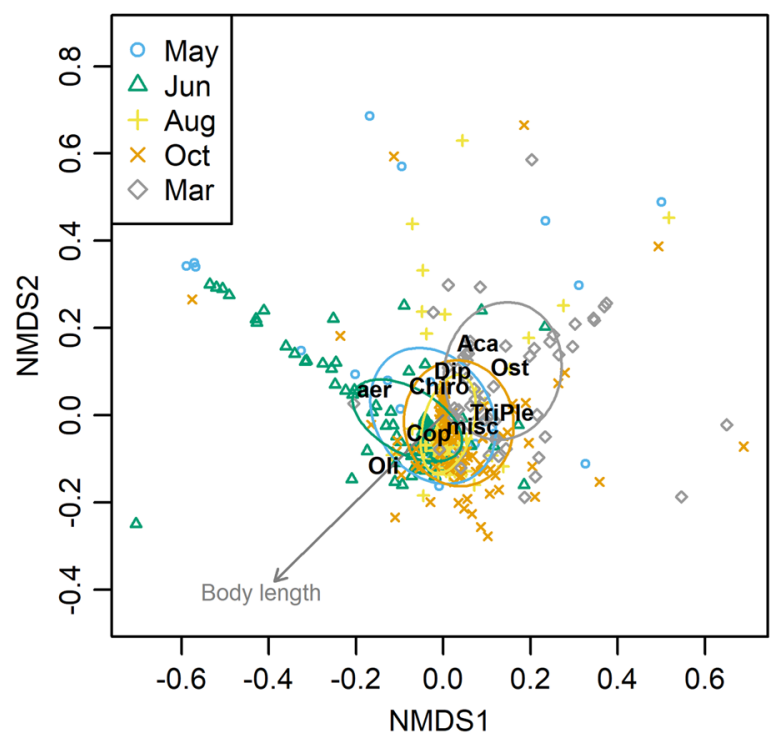

Table 2), so no vector is shown. Note that the direction of a vector indicates whether prey groups are positively (or negatively) correlated with it and the further the centroid of a group is along (or in the opposite direction to) the vector, the stronger the correlation. Prey groups are abbreviated as follows: Chiro (Chironomidae larvae), Ost (Ostracoda), Cop (Copepoda), Aca (Acarina), Tri.Ple (Trichoptera/Plecoptera larvae), Dip (predatory Diptera larvae), Oli (Oligochaeta), aer (aerial insects), and misc (miscellaneous)

Dominant prey groups in the fish stomachs, such as Chironomidae larvae and Copepoda, partly reflected invertebrate availability in the environment (Fig. 3). The high proportion of aerial insects in the fish diet in June (Fig. 2b) coincided with emergence and oviposition of most aquatic insects (Hannesdóttir et al., 2013), during which fish can easily pick them off from the water surface. Mass emergences of Chironomidae are known to be a critical energy subsidy for fish and ducks (Einarsson \& Gardarsson, 2004; Einarsson et al., 2004).

There was no clear evidence that Arctic charr exhibited stronger feeding selectivity for invertebrate groups when their availability in the environment was high, in contrast to our third hypothesis. One clear exception to this was for Chironomidae in June, coinciding with their highest absolute abundance in the environment (Fig. 4a). Note that many species of Chironomidae larvae are in their last and largest larval stage before pupation around this time of year (Hannesdóttir et al., 2013), and thus are potentially 
more attractive prey items. In contrast, the feeding preference of fish for Trichoptera/Plecoptera larvae was highest in March, when general invertebrate availability was low (Figs. 3e,4e). Arctic charr also tended to prefer predatory Diptera larvae in August and October (Figs. 3f,4f), even though they were among the rarest invertebrate groups in the environment (Fig. 2). The protein-rich diet of predatory Diptera larvae may make them a more profitable food source than primary consumers (Cummins \& Klug, 1979; O'Gorman et al., 2016). In support of this, fish with a better body condition were found to prefer predatory Diptera larvae, whereas fish with a feeding preference for Chironomidae larvae were associated with a poorer body condition (Fig. 5a). It seems that fish are not achieving the best body condition if they feed on the small, abundant prey in the system, but rather when they feed selectively on large, rare, and more energetically valuable resources. Similarly, brown trout (Salmo trutta Linnaeus, 1758) has been shown to invest more time in finding large, rare prey in energetically demanding environments (O'Gorman et al., 2016). Body condition could thus be a direct result of the choice of prey, or the choice of prey may be dictated by constraints imposed by body condition, mediated for example through competition as discussed below.

Seasonal variation in the abundance of the miscellaneous group in the fish diet was likely due to differences in the ecology (e.g. timing of reproduction, microhabitat use) or phenotype (e.g. body size) between the constituent taxa. Cladocera and aquatic Coleoptera were prevalent in the fish diet in October and groundwater amphipods in March. All amphipods found in the stomach samples belonged to Crangonyx islandicus Svavarsson \& Kristjánsson, 2006, with the exception of a single Crymostigius thingvallensis Kristjánsson \& Svavarsson, 2004. Both amphipod species are endemic to Iceland, but whereas the former is relatively common in cold springs across the country (Kristjánsson \& Svavarsson, 2007), the latter is rare. This is only the second time $C$. thingvallensis has been recorded outside of the lake Pingvallavatn (Kristjánsson \& Svavarsson, 2007). The dietary shift to groundwater amphipods during the winter might imply that spring-dwelling small benthic Arctic charr moves deeper into the groundwater during that time of year. This could either be due to a food shortage in the surface stream, or the more favourable stable thermal conditions in the groundwater, which is unaffected by snowfall and wind. The higher preference for Ostracoda, Trichoptera larvae, and Plecoptera nymphs in winter also indicates a shift towards benthic prey. Similar results have been shown for brown trout in Minnesota streams, which rely more on benthic prey than on drift during the winter (Anderson et al., 2016), but mostly consume drifting prey in summer (Bachman, 1984).

In accordance with our third hypothesis, the population-wide prevalence of individual specialisation was highest in March when total invertebrate abundance was low (Table 1). It could be advantageous for an individual to specialise on a prey group that its conspecifics do not feed on at times when food availability is low to avoid intrapopulation competition. In a study on benthic isopods, the degree of diet specialisation was negatively correlated with resource abundance, not forager densities, suggesting that exploitative competition is the driver behind diet specialisation (Svanbäck et al., 2011). Competition for resources could be mediated by body size, as larger fish in our study showed stronger individual specialisation (Table 2b). A good example here was the preference of larger fish for Oligochaeta (see Fig. 5b), which were dominated by larger earthworms in our study. Earthworms are likely to be too large a prey item for smaller fish, which specialised instead on tiny Ostracoda and Acarina. The importance of Oligochaeta is often overlooked in the diet of freshwater fish, even though their energy content per unit of dry mass is almost as high as for insects (Brey et al., 1988). Oligochaeta of both aquatic and terrestrial origin (washed into streams following heavy rainfall) have also been shown to play a potentially important role in the diet of salmonids during summer months (Aarefjord et al., 1973).

Another explanation for greater differences in diet among individuals at times of lower prey abundance could be the higher stochasticity in the resources that individuals encounter, and diet differences would thus be driven more by prey availability rather than individual choice.

Kristjánsson \& Leblanc (2018) found that spring type influenced individual specialisation of Arctic charr, with higher diet similarity among individuals of a population in streams than in ponds. The more variable diet of fish in ponds was due to a higher diversity of crustaceans associated with that habitat, 
although their study did not take seasonal changes in community composition into account (Kristjánsson \& Leblanc, 2018). Our results show that crustaceans are also important food for Arctic charr in streamassociated springs during the winter, which might contribute to the stronger individual specialisation in March. This implies that both habitat variability and temporal variability of individual specialisation could be driven by similar mechanisms (i.e. composition of invertebrate prey).

The growth rates of recaptured fish were much lower between May-June than between June-August and August-October. This was not surprising, since the invertebrate abundance in the benthic substrate of the spring was highest between June and October (Table 1), and fish had plenty to feed on. Somatic growth rate is positively correlated with quantitative food intake in Arctic charr, and influenced by intraspecific competition for limited resources (Amundsen et al., 2007).

The patchy distribution of fish in the sampled area was striking. Most fish were caught in or near the spring sources, a few from under the overhanging stream bank, but almost none were found in the open area of the stream. The main channel of the stream, which does not have spring sources, contained a lot less Arctic charr than the other, source-rich sampling zones (Fig. 1), indicating that the fish prefer the spring sources as habitat. This may be due to the stable groundwater temperature and/or a higher abundance and diversity of invertebrate prey (e.g. groundwater amphipods make an important contribution to the winter diet of Arctic charr). The variety of microhabitats around the sources (e.g. mosses, macrophytes, lava rock) may also offer protection from predators such as brown trout, which occurs in the stream and feeds on small benthic Arctic charr. During early summer, a colony of Arctic tern (Sterna paradisaea Pontoppidan, 1763) uses the meadows around the spring as a nesting site, and terns have been observed feeding on Arctic charr in the open stream during the June sampling. High predation pressure in the summer months could also contribute to the lower individual specialisation during that time of the year (Aráujo et al., 2011). Under high predation pressure, prey might seek shelter in the same protected microhabitat and thus use a similar dietary niche (Werner et al., 1983).

\section{Conclusion}

The observed division into a winter and summer community, even though water temperature remained constant, emphasises the need for repeated sampling over more than one season for a complete characterisation of spring invertebrate communities. This seasonal variation in invertebrate availability also affected the diet, feeding selectivity, individual specialisation, growth rates, and biomass of Arctic charr. Feeding preferences for the dominant Chironomidae larvae indicated that the population preferred the most abundant prey during summer, which resulted in a narrower population niche width. The proportion of individual specialisation within the population, on the other hand, was higher in winter, which could be a strategy to relax intra-species competition at times when food resources are less abundant. This resulted in a broader population niche width, but a narrower individual niche width during winter, highlighting the value of studying both population-level selectivity and individual-level specialisation in studies on fish diet. Overall, we have demonstrated that seasonal variation in invertebrate communities can affect higher trophic levels, which should be considered when interpreting the behaviour (e.g. feeding ecology) and phenotype (e.g. growth rates) of fish in field studies.

Acknowledgements Thanks to the people involved in the fieldwork for this project: Zophonías O. Jónsson, Jake Goodall, Sebastien Matlosz, and Marlène Kundruhn. Leivur Janus Hansen created the map of the sampling site in Fig. 1 and contributed comments and discussions. Thanks to Gísli Már Gíslason for commenting on the manuscript. The project was funded by the Icelandic Research Fund (RANNÍS), Grants nr. 141863-051 and 185083-051, and by Náttúruverndarsjóður Pálma Jónssonar.

Open Access This article is licensed under a Creative Commons Attribution 4.0 International License, which permits use, sharing, adaptation, distribution and reproduction in any medium or format, as long as you give appropriate credit to the original author(s) and the source, provide a link to the Creative Commons licence, and indicate if changes were made. The images or other third party material in this article are included in the article's Creative Commons licence, unless indicated otherwise in a credit line to the material. If material is not included in the article's Creative Commons licence and your intended use is not permitted by statutory regulation or exceeds the permitted use, you will need to obtain permission directly from the copyright holder. To view a copy of this licence, visit http://creativecommons.org/licenses/by/4.0/. 
Data availability The data that support the findings of this study are available from the corresponding author upon reasonable request.

\section{References}

Aarefjord, F., R. Borgström, L. Lien \& G. Milbrink, 1973. Oligochaetes in the bottom fauna and stomach of trout, Salmo trutta (L.). Norwegian Journal of Zoology 21: 281-288.

Amundsen, P.-A., R. Knudsen \& A. Klemetsen, 2007. Intraspecific competition and density dependence of food consumption and growth in Arctic charr. Journal of Animal Ecology 76: 149-158.

Anderson, N. H. \& K. W. Cummins, 1979. Influences of diet on the life histories of aquatic insects. Journal of the Fisheries Board of Canada 36: 335-342.

Anderson, A. M., E. Mittag, B. Middleton, B. Vondracek \& L. C. Ferrington, 2016. Winter diets of Brown trout populations in Southeastern Minnesota and the significance of winter-emerging invertebrates. Transactions of the American Fisheries Society 145: 206-220.

Araújo, M. S., D. I. Bolnick \& C. A. Layman, 2011. The ecological causes of individual specialisation. Ecology Letters 14: 948-958.

Bachman, R. A., 1984. Foraging behaviour of free-ranging wild and hatchery Brown trout in a stream. Transactions of the American Fisheries Society 113: 1-32.

Barnham, C. \& A. Baxter, 1998. Condition Factor, K, for salmonid fish. Fisheries Notes 5: 1-3.

Berlajolli, V., M. Plóciennik, O. Antczak-Orlewska \& V. Pešić, 2019. The optimal time for sampling macroinvertebrates and its implications for diversity indexing in rheocrenescase study from the Prokletije Mountains. Knowledge \& Management of Aquatic Ecosystems 420: 6.

Bolnick, D. I., L. H. Yang, J. A. Fordyce, J. M. Davis \& R. Svanbäck, 2002. Measuring individual-level resource specialization. Ecology 83: 2936-2941.

Bolnick, D. I., R. Svanbäck, J. A. Fordyce, L. H. Yang, J. M. Davis, C. D. Hulsey \& M. L. Forister, 2003. The ecology of individuals: incidence and implications of individual specialization. The American Naturalist 161: $1-28$.

Bottazzi, E., M. C. Bruno, V. Pieri, A. Di Sabatino, L. Silveri, M. Carolli \& G. Rossetti, 2011. Spatial and seasonal distribution of invertebrates in Northern Apennine rheocrene springs. Journal of Limnology 70: 77-92.

Brey, T., H. Rumohr \& S. Ankar, 1988. Energy content of macrobenthic invertebrates: general conversion factors from weight to energy. Journal of Experimental Marine Biology and Ecology 117: 271-278.

Britton, J. R. \& D. Andreou, 2016. Parasitism as a driver of trophic niche specialisation. Trends in Parasitology 32: 437-445.

Brown, J. H., J. F. Gillooly, A. P. Allen, V. M. Savage \& G. B. West, 2004. Toward a metabolic theory of ecology. Ecology 85: 1771-1789.
Burgmer, T., H. Hillebrand \& M. Pfenninger, 2007. Effects of climate-driven temperature changes on the diversity of freshwater macroinvertebrates. Oecologia 151: 93-103.

Chesson, J., 1983. The estimation and analysis of preference and its relatioship to foraging models. Ecology 64: 1297-1304.

Clarke, K. R., P. J. Somerfield \& M. G. Chapman, 2006. On resemblance measures for ecological studies, including taxonomic dissimilarities and a zero-adjusted Bray-Curtis coefficient for denuded assemblages. Journal of Experimental Marine Biology and Ecology 330: 55-80.

Costa, G. C., D. O. Mesquita, G. R. Colli \& L. J. Vitt, 2008. Niche expansion and the niche variation hypothesis: does the degree of individual variation increase in depauperate assemblages? The American Naturalist 172: 868-877.

Cummins, K. W. \& M. J. Klug, 1979. Feeding ecology of stream invertebrates. Annual Review of Ecology and Systematics 10: $147-172$.

Darimont, C. T., P. C. Paquet \& T. E. Reimchen, 2007. Stable isotopic niche predicts fitness of prey in a wolf-deer system. Biological Journal of the Linnean Society 90: 125-137.

Einarsson, Á. \& A. Gardarsson, 2004. Moulting diving ducks and their food supply. Aquatic Ecology 38: 297-307.

Einarsson, Á., G. Stefánsdóttir, H. Jóhannesson, J. S. Ólafsson, G. M. Gíslason, I. Wakana, G. Gudbergsson \& A. Gardarsson, 2004. The ecology of Lake Myvatn and the River Laxá: variation in space and time. Aquatic Ecology 38: 317-348.

Emlen, J. M., 1966. The role of time and energy in food preference. The American Naturalist 100: 611-617.

Evans, M. C., C. Macgregor \& P. J. Jarman, 2006. Diet and feeding selectivity of common wombats. Wildlife Research 33: 321-330.

Feinsinger, P., E. E. Spears \& R. W. Poole, 1981. A simple measure of niche breadth. Ecology 62: 27-32.

Gíslason, G. M., 1978. Life cycle of Limnephilus affinis Curt. (Trichoptera: limnephilidae) in Iceland and in Northumberland, England. Verhandlungen der Internationale Vereinigung für Theoretische und Angewandte Limnologie 20: 2622-2629.

Gíslason, G.M. 1992. Life history strategies of Icelandic Trichoptera. In Tomaszewski (Ed.). Proceedings of the Sixth International Symposium on Trichoptera. Adam Mickiewicz University Press, Poznan, Poland.

Hannesdóttir, E. R., G. M. Gíslason, J. S. Ólafsson, Ó. P. Ólafsson \& E. J. O’Gorman, 2013. Increased stream productivity with warming supports higher trophic levels. Advances in Ecological Research 48: 285-342.

Haslett, J. R., 1989. Interpreting patterns of resource utilization: randomness and selectivity in pollen feeding by adult hoverflies. Oecologia 78: 433-442.

Jones, C. \& G. Norbury, 2011. Feeding selectivity of introduced hedgehogs Erinaceus europeus in a dryland habitat, South Island, New Zealand. Acta Theriologica 56: 45-51.

Klecka, J. \& D. S. Boukal, 2012. Who eats whom in a pool? A comparative study of prey selectivity by predatory aquatic insects. PloS One 7: e37741.

Klemetsen, A., 2013. The most variable vertebrate on earth. Journal of Ichthyology 53: 781-791. 
Kristjánsson, B. K. \& J. Svavarsson, 2007. Subglacial refugia in Iceland enabled groundwater amphipods to survive glaciation. The American Naturalist 170: 292-296.

Kristjánsson, B. K. \& C. A. Leblanc, 2018. Variation in the magnitude of morphological and dietary differences between individuals among populations of small benthic Arctic charr in relation to ecological factors. Ecology and Evolution 8: 1573-1581.

Kristjánsson, B. K., S. Skúlason, S. S. Snorrason \& D. L. G. Noakes, 2012. Fine-scale parallel patterns in diversity of small benthic Arctic charr (Salvelinus alpinus) in relation to the ecology of lava/groundwater habitats. Ecology and Evolution 2: 1099-1112.

Lechowicz, M. J., 1982. The sampling characteristics of electivity indices. Oecologia 52: 22-30.

Lutz, P. E., 1974. Environmental factors controlling duration of larval instars in Tetragoneuria cynosure (Odonata). Ecology 55: 630-637.

Malmquist, H. J., S. S. Snorrason, S. Skúlason, B. Jonsson, O. T. Sandlund \& P. M. Jonasson, 1992. Diet differentiation in polymorphic Arctic charr in Thingvallavatn, Iceland. Journal of Animal Ecology 61: 21-35.

Meehan, W. R. \& R. A. Miller, 1978. Stomach flushing: effectiveness and influence on survival and condition of juvenile salmonids. Journal of the Fisheries Research Board of Canada 35: 1359-1363.

Nolte, U., 1991. Seasonal dynamics of moss-dwelling chironomid communities. Hydrobiologia 222: 197-211.

Nylin, S. \& K. Gotthard, 1998. Plasticity in life-history traits. Annual Review of Entomology 43: 63-83.

O’Gorman, E., Ó. P. Ólafsson, B. O. L. Demars, N. Friberg, G. Guðbergsson, E. R. Hannesdóttir, M. C. Jackson, L. S. Johansson, Ó. B. McLaughlin, J. S. Ólafsson, G. Woodward \& G. M. Gíslason, 2016. Temperature effects on fish production across a natural thermal gradient. Global Change Biology 22: 3206-3220.

O'Gorman, E. J., L. Zhao, D. E. Pichler, G. Adams, N. Friberg, B. C. Rall, A. Seeney, H. Zhang, D. C. Reuman \& G. Woodward, 2017. Unexpected changes in community size structure in a natural warming experiment. Nature Climate Change 7: 659 .

O'Gorman, E. J., O. L. Petchey, K. J. Faulkner, B. Gallo, T. A. C. Gordon, J. Neto-Cerejeira, J. S. Ólafsson, D. E. Pichler, M. S. A. Thomson \& G. Woodward, 2019. A simple model predicts how warming simplifies wild food webs. Nature Climate Change 9: 611-616.

Oksanen, J., Blanchet, F.G., Friendly, M., Kindt, R., Legendre, P., McGlinn, D., Minchin, P.R., O'Hara, R.B., Simpson, G.L., Solymos, P., Stevens, M.H.H., Szoecs, E. and Wagner, H. 2017. Vegan: community ecology package. R package version 2.4-4. https://CRAN.R-project.org/ package $=$ vegan

Pennak, R. W., 1953. Freshwater invertebrates of the United States. The Ronald Press Company, New York: 769.

Petchey, O. L., P. T. McPhearson, T. M. Casey \& P. J. Morin, 1999. Environmental warming alters food-web structure and ecosystem function. Nature 402: 69-72.

Robson, D. S. \& H. A. Regier, 1964. Sample size in Petersen mark-recapture experiments. Transactions of the American Fisheries Society 93: 215-226.
Schaefer, H. M. \& V. Schaefer, 2006. The fruits of selectivity: how birds forage on Goupia glabra fruits of different ripeness. Journal of Ornithology 147: 638-643.

Schmidt, H.-W., 1969. Tages- und jahresperiodische Driftaktivität der Wassermilben (Hydrachnellae, Acari). Oecologia 3: 240-248.

Schoener, T. W., 1968. The Anolis lizards of Bimini: resource partitioning in a complex fauna. Ecology 49: 704-726.

Schoener, T. W., 1971. Theory of feeding strategies. Annual Review of Ecology and Systematics 2: 369-404.

Shama, L. N. S. \& C. T. Robinson, 2006. Sex-specific lifehistory responses to seasonal time constraints in an alpine caddisfly. Evolutionary Ecology Research 8: 169-180.

Shurin, J. B., J. L. Clasen, H. S. Greig, P. Kratina \& P. L. Thompson, 2012. Warming shifts top-down and bottomup control of pond food web structure and function. Philosophical Transactions of the Royal Society B 367: 3008-3017.

Skúlason, S., D. L. G. Noakes \& S. S. Snorrason, 1989. Ontogeny of trophic morphology in four sympatric morphs of arctic charr Salvelinus alpinus in Thingvallavatn, Iceland. Biological Journal of the Linnean Society 38: 281-301.

Skúlason, S., S. S. Snorrason, D. L. G. Noakes \& M. M. Ferguson, 1996. Genetic basis of life history variations among sympatric morphs of Arctic char, Salvelinus alpinus. Canadian Journal of Fisheries and Aquatic Sciences 53: 1807-1813.

Stephens, D. W. \& J. R. Krebs, 1986. Foraging Theory. Princeton University Press, Princeton, New Jersey: 247.

Svanbäck, R., C. Rydberg, K. Leonardsson \& G. Englund, 2011. Diet specialization in a fluctuating population of Saduria entomon: a consequence of resource or forager densities? Oikos 120: 848-854.

Szczucinska, A. M. \& H. Wasielewski, 2013. Seasonal water temperature variability of springs from porous sediments in Gryzynka Valley, Western Poland. Quaestiones Geographicae 32: 111-117.

R Core Team 2016. R: a language and environment for statistical computing. R Foundation for Statistical Computing, Vienna, Austria. https://www.R-project.org/.

Tinker, M. T., P. R. Guimaraes, M. Novak, F. M. D. Marquitti, J. L. Bodkin, M. Staedler, G. Bentall \& J. A. Estes, 2012. Structure and mechanism of diet specialisation: testing models of individual variation in resource use with sea otters. Ecology Letters 15: 475-483.

Tófoli, R. M., G. H. Z. Alves, J. Higuti, A. M. Cunico \& N. S. Hahn, 2013. Diet and feeding selectivity of a benthivorous fish in streams: responses to the effects of urbanization. Journal of Fish Biology 83: 39-51.

Uieda, V. S. \& T. L. F. Pinto, 2011. Feeding selectivity of ichthyofauna in a tropical stream: space-time variations in trophic plasticity. Community Ecology 12: 31-39.

van der Kamp, G., 1995. The hydrogeology of springs in relation to the biodiversity of spring fauna: a review. Journal of the Kansas Entomological Society 68: 4-17.

Vanderploeg, H. A. \& D. Scavia, 1979. Two electivity indices for feeding with special reference to zooplankton grazing. Journal of the Fisheries Research Board of Canada 36: 362-365. 
Ward, J. V. \& J. A. Stanford, 1982. Thermal responses in the evolutionary ecology of aquatic insects. Annual Review of Entomology 27: 97-117.

Werner, E. E., G. G. Mittelbach, D. J. Hall \& J. F. Gillam, 1983. Experimental tests of optimal habitat use in fish: the role of relative habitat profitability. Ecology 64: 1525-1539.

Zango, L., J. M. Reyes-González, T. Militão, Z. Zajková, E. Álvarez-Alonso, R. Ramos \& J. González-Solís, 2019. Year-round individual specialization in the feeding ecology of a long-lived seabird. Scientific Reports 9: 1-12.
Zwarts, L. \& A.-M. Blomert, 1990. Selectivity of whimbrels feeding on fiddler crabs explained by component specific digestibilities. Ardea 78: 193-208.

Publisher's Note Springer Nature remains neutral with regard to jurisdictional claims in published maps and institutional affiliations. 